\title{
Prevalence of advance directives among elderly patients attending an urban Canadian emergency department
}

\author{
Ginjeet Gina K. Gill, MD*; Erin Fukushima, MD; ${ }^{\dagger \ddagger}$ Riyad B. Abu-Laban, MD, MHSc ${ }^{\dagger \ddagger \S}$; \\ David D. Sweet, MD
}

\section{ABSTRACT}

Introduction: To date, there has been minimal research on advance directives (ADs) among elderly patients in Canadian emergency departments (EDs). The purpose of this study was to determine the prevalence of ADs among elderly patients visiting an urban ED. We also explored whether there were factors associated with the existence of an $A D$ and possible barriers to having one.

Methods: This prospective study ran between October and December 2008. Individuals over the age of 70 who presented to the ED between 7 am and 7 pm, 7 days a week, were considered for enrolment. Exclusion criteria included previous enrolment and inability to provide informed consent. A team of nurses who specialize in assessment of geriatric patients administered a study instrument consisting of 28 questions. Topics included demographics, level of education, medical information, and knowledge of and attitudes toward ADs.

Results: The results from 280 participants, with an average age of 80.6 years, were analyzed. Thirty-five percent of participants reported that they knew what an AD was; $19.3 \%$ of participants said they had an $A D$, but only $5.6 \%$ brought it to the hospital; $50.7 \%$ were interested in further information regarding $A D s$; and $67.9 \%$ of participants felt that it was important for physicians to know their wishes about life support.

Conclusion: Knowledge of ADs among elderly patients visiting an urban Canadian ED is limited and is likely a significant factor precluding wider prevalence of ADs. There is interest in further discussion about ADs in this population group.

\section{RÉSUMÉ}

Introduction: À ce jour, peu de recherches ont été effectuées sur les directives préalables (DP) pour les patients âgés dans les services des urgences (SU) au Canada. La présente étude vise à établir la prévalence des DP pour les patients âgés qui se rendent dans un SU en milieu urbain. Nous avons aussi vérifié s'il y avait des facteurs associés à l'existence de DP et les obstacles possibles à des DP.

Méthodes: Cette étude prospective a été réalisée entre octobre et décembre 2008. Les participants étaient des individus âgés de 70 ans et plus qui se sont rendus dans un service des urgences entre 7 et 19 h, 7 jours sur 7 . Les critères d'exclusion comprenaient la participation antérieure et l'incapacité de donner son consentement éclairé. Une équipe d'infirmières spécialisées dans l'évaluation des malades gériatriques ont administré un instrument d'étude comportant 28 questions. Les sujets abordés comprenaient des renseignements d'ordre statistique, le degré de scolarité, des renseignements médicaux, ainsi que les connaissances et les perceptions relatives aux DP.

Résultats: Les résultats de 280 participants dont la moyenne d'âge était de 80,6 ans ont été analysés. Trente-cinq pour cent des participants ont dit savoir ce qu'était une DP; $19,3 \%$ des participants ont dit qu'ils avaient une DP, mais seulement 5,6 \% I'ont apportée à l'hôpital; 50,7 \% des participants étaient intéressés à en savoir davantage sur les DP; et 67,9\% des participants trouvaient qu'il était important pour les médecins de connaître leurs désirs concernant le maintien des fonctions vitales.

Conclusion: La connaissance des DP chez les patients âgés qui se rendent dans un SU en milieu urbain au Canada est limitée et est probablement un facteur important qui empêche d'avoir une plus grande prévalence des DP. Ce groupe de la population est intéressé à discuter davantage des DP.

Keywords: advance directives, advance health care planning, code status, do not resuscitate, end of life, living will

From the *FRCP Emergency Medicine Residency Program, University of British Columbia; †Department of Emergency Medicine, Vancouver General Hospital; ‡Department of Emergency Medicine, University of British Columbia; §Centre for Clinical Epidemiology and Evaluation, Vancouver Coastal Health Research Institute; and IIDivision of Critical Care, University of British Columbia, Vancouver, BC.

Correspondence to: Dr. Ginjeet Gina K. Gill, Department of Emergency Medicine, Vancouver General Hospital, 855 West 12th Avenue, Vancouver, BC V5Z 1M9; ginagill@gmail.com.

This article has been peer reviewed. 
Many doctors face end-of-life decisions surrounding patient care. Advanced care planning is a process whereby patients, in consultation with their health care providers, significant others, and family members, make decisions about future health care. These decisions can be documented as an advance directive (AD), a living will, the identification of a proxy decision maker, or a combination thereof. ADs help health care providers respect the wishes of patients who are unable to communicate. Without an $\mathrm{AD}$, a physician or surrogate decision maker may be forced to make assumptions, potentially influenced by their own biases, regarding patient's beliefs and preferences.

In 1991, the United States passed the Patient SelfDetermination Act, whereby all hospitals in the United States were required to inform patients of their right to make end-of-life decisions and to incorporate any such decisions into patients' medical records. Despite this, studies in both inpatient and outpatient settings in the United States indicate that the prevalence of ADs is only 15 to $25 \% .^{1-4}$ Moreover, other studies suggest that even when patients have ADs, the existence or specifics of these directives may not be communicated to primary health care providers..$^{5-7}$

The emergency department (ED) represents a unique setting where physicians frequently encounter patients for the first time and are unfamiliar with their values and beliefs regarding end-of-life care. Moreover, EDs frequently treat critically ill patients, many of whom are not able to communicate with hospital staff, at times without the benefit of an identified substitute decision maker. In such situations, an $\mathrm{AD}$ clearly expressing a patient's wishes may be the only immediately available guide for the care initiated by emergency health care providers.

To our knowledge, the prevalence of $\mathrm{ADs}$ among Canadian ED patients has not been described. The purpose of this study was to determine the prevalence of ADs among elderly patients visiting a tertiary Canadian ED. In addition, we sought to determine whether any factors were associated with the existence of an $\mathrm{AD}$ and to explore possible barriers to having one.

\section{METHODS}

\section{Setting and study population}

This prospective cohort study was carried out from October through December 2008 at the Vancouver
General Hospital (VGH), an urban, tertiary academic centre with an annual ED census of approximately 75,000 patient visits. During the study period, all ED patients over the age of 70 years were identified using the hospital's patient care information system. Consecutive patients who visited the ED between 7 am and $7 \mathrm{pm}, 7$ days per week, were considered for enrolment.

We developed a survey instrument, which was administered by a team of nurses in the ED who specialize in the assessment of geriatric patients. These geriatric triage nurses (GTNs) assess patients over the age of 70 who visit the VGH ED between 7 am and 7 pm daily. Assessment by a GTN in addition to routine ED care has been standard practice in our ED since 2003. Their standard assessment is multifactorial and involves assessment of daily activities, fall risk, social supports, and discharge planning, including the need for possible further community supports. During the study period, the GTN on duty regularly reviewed the ED census to identify patients who met the study inclusion criteria.

\section{Inclusion and exclusion criteria}

We included ED patients $\geq 70$ years of age. We excluded previously enrolled patients and those unable to provide informed consent, whether due to dementia, psychosis, altered level of consciousness, language barrier, or acuity of illness, combined with the absence of a substitute decision maker. All participants or their substitute decision maker provided written informed consent.

\section{Survey}

We developed a three-part survey instrument to be administered by the GTNs. The instrument was in English, in large font, and consisted of 28 questions. To make data collection easier, the majority of responses were in tick-box format. The survey instrument was read to participants and completed by the GTNs.

The first section of the instrument focused on demographic information. The next section of the instrument focused on medical history, quality of life, and functional status. The final section of the instrument was about knowledge and possession of ADs. Opinions were sought as to whether patients 
felt ADs were necessary and, if so, who would be appropriate to assist in completing one. In the case of participants without an $\mathrm{AD}$, we inquired as to reasons for this and whether there was interest on the participant's part to establish an $\mathrm{AD}$ in the future.

\section{Ethical approval}

This study was approved by the Research Ethics Board (REB) of the University of British Columbia. Our REB precluded us from collecting any information, even of a baseline demographic nature, on patients who declined participation.

\section{Statistical analysis}

Data were entered into a Microsoft Excel spreadsheet, and basic statistical analyses were conducted using its software. Descriptive data were derived from this. Binomial 95\% confidence intervals were calculated using Stata version 5.0, MacIntosh (StataCorp, College Station, TX). A logistic regression model was used to examine six factors selected a priori as potentially associated with the presence of an $\mathrm{AD}$ : age, ability to perform independent activities of daily living, personal or secondary experience with the intensive care unit (ICU), level of education, perception of the presence of a life-threatening disease, and having a specialist physician. Each factor was forced into the model without univariate testing or a prespecified $p$ value for inclusion or exclusion. Regression diagnostics were not performed, and the model was fit using SPSS version 10.0, MacIntosh (SPSS Inc., Chicago, IL).

\section{RESULTS}

Figure 1 outlines the derivation of the study population. During the study hours, 1,135 unique visits by individuals over the age of 70 were seen by the GTNs. Of these, 129 could not be assessed because of high GTN workload and 589 patients were not eligible to participate because of inability to provide informed consent. Informed consent was provided by 283 of 417 eligible participants $(67.9 \%)$, including at least 40 cases in which a family member provided consent. Three participants later withdrew from the study, leaving 280 completed surveys for analysis.

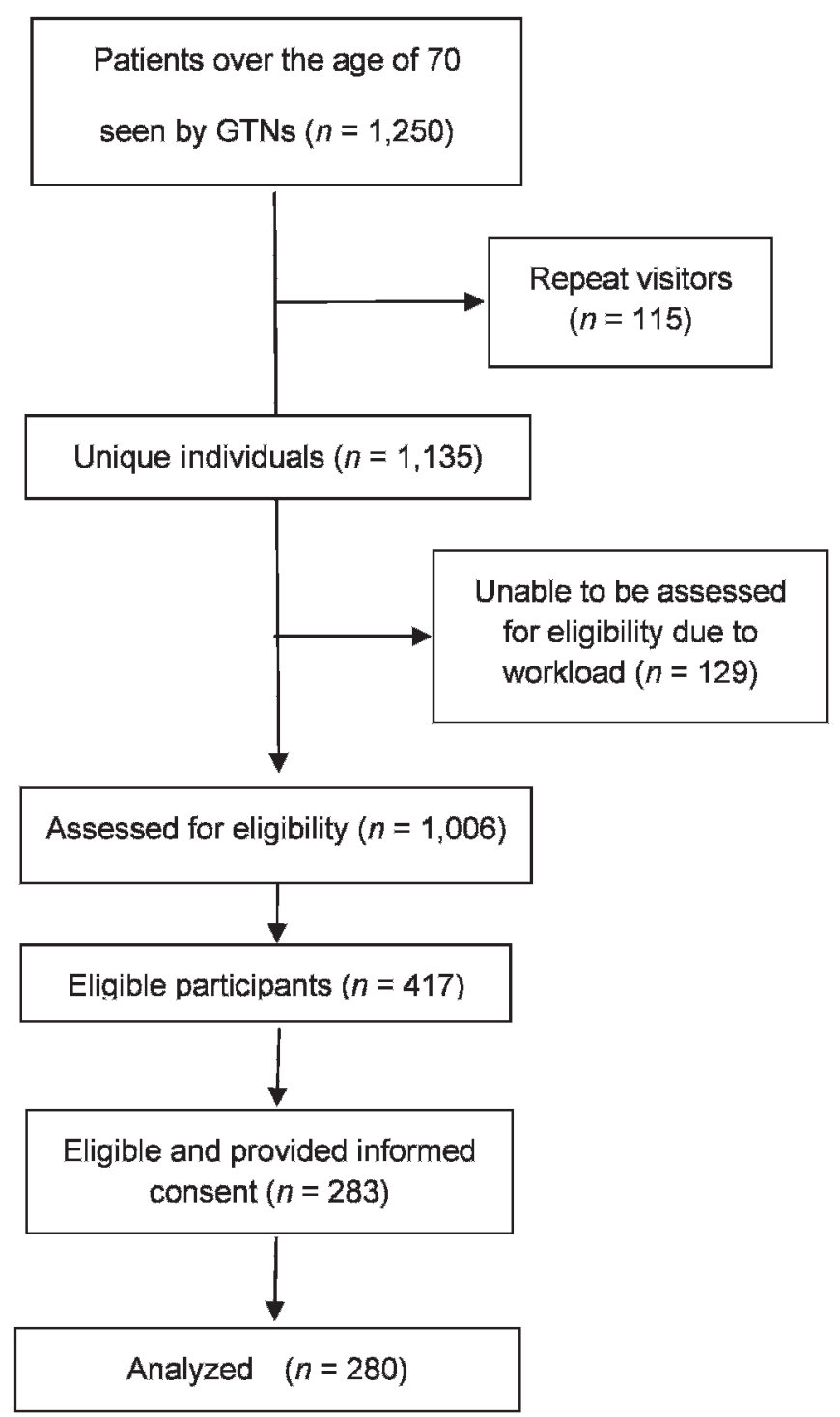

Figure 1. Recruitment and flow of patients. GTN = geriatric triage nurse.

\section{Demographics}

Table 1 provides demographic information on the study population. The average age was 80.6 years. The majority of participants were raised in Canada and fluent in English. A total of 215 respondents (76.8\%) reported having at least a high school level of education. Only a minority of the participants resided in either assisted-living accommodations or nursing homes.

\section{Health status}

Almost all participants indicated that they had a primary care physician (97.9\%). On average, patients had 2.8 medical diagnoses (range 0-10) and were taking 4.3 


\begin{tabular}{lc|}
\hline Table 1. Participant characteristics & \\
\hline Characteristic & $n(\%)$ \\
\hline Average age, yr & 80.6 \\
Male:female & $126(45 \%)$ : \\
& $154(55 \%)$ \\
Have living children ( $n=279)^{*}$ & $229(81.8)$ \\
Raised in Canada & $164(56.8)$ \\
Fluent in English & $256(91.4)$ \\
Level of education & \\
$<$ High school & $65(23.2)$ \\
High school & $86(30.7)$ \\
College, university, or postgraduate & $127(45.4)$ \\
Did not answer question & $2(0.7)$ \\
Living situation & \\
Alone & $118(42.1)$ \\
With spouse or partner & $82(29.3)$ \\
With other family & $51(8.2)$ \\
Assisted living & $18(6.4)$ \\
Nursing home & $6(2.1)$ \\
Other & $5(1.8)$ \\
Have a family physician $(n=275)^{*}$ & $274(97.9)$ \\
Have a specialist physician $(n=270)^{*}$ & $152(54.3)$ \\
Have a life-threatening disease $(n=275)^{*}$ & $43(15.4)$ \\
Have had prior "ICU experience" $(n=267)^{*}$ & $94(33.6)$ \\
Capable of ADL ( $n=272)^{*}$ & $238(85.0)$ \\
Capable of IADL ( $n=270)^{*}$ & $201(71.8)$ \\
Know what an advance directive is $(n=272)^{*}$ & $98(35.0)$ \\
Have an advance directive $(n=271)^{*}$ & $54(19.3)$ \\
\hline ADL =activities of daily living; IADL $=$ instrumental activities of daily living; ICU & \\
intensive care unit. & \\
$*$ for the purposes of calculations $n=280$ was used. & \\
& \\
& \\
\hline
\end{tabular}

medications (range 0-15). When asked to rank their health on a scale of 0 to 5 , with 0 indicating "very poor" and 5 indicating "excellent," the average response was 3.6. Participants were also asked to rank their quality of life on the same scale, and the average rank was 3.8.

Based on the assessment by the GTNs, 238 (85.0\%) participants were capable of attending to all of their activities of daily living, such as dressing, grooming, and feeding. In addition, $201(71.8 \%)$ participants were capable of doing all of their instrumental activities of daily living, including housework, cooking, banking, and shopping.

Approximately one-third of participants (33.6\%) had some level of familiarity with the ICU, either as a patient or indirectly through the experience of a friend or loved one.

\section{Advance directives}

Of the 280 participants, 98 (35.0\%; 95\% CI 29.4-40.9) reported that they knew what an $\mathrm{AD}$ was. Fifty-four
(19.3\%; 95\% CI 14.8-24.4) participants said that they had an $\mathrm{AD}$, but only 3 (5.6\%; 95\% CI 11.6-15.4) brought it to the hospital.

Table 2 provides information on the features of ADs in the study population. Of the 54 participants who had ADs, $28(51.9 \%)$ reported that their family doctor was aware of the AD. Whereas 32 (61.5\%) participants had drawn up their ADs with a lawyer, only 10 participants (19.2\%) had done so with the help of a family doctor.

Table 3 compares $\mathrm{AD}$ knowledge and ownership within prespecified subgroups of the study population. The responses of participants were similar whether they were raised in Canada, had some degree of experience with the ICU (either as a patient or by knowing a loved one who was in an ICU), or identified themselves as having a life-threatening disease.

Table 4 lists common reasons for not having an $\mathrm{AD}$ provided by the 226 participants without ADs. In this group, $47.3 \%$ reported having never thought about it as the main reason for not having one.

All participants were asked if they thought it would be important for doctors to know their wishes about life support prior to becoming critically ill: 190 $(67.9 \%)$ believed that it would be important, and 55 $(19.6 \%)$ believed that it was not important. The remaining $12.5 \%$ did not respond to this question. When participants were asked about whether they

\begin{tabular}{|c|c|}
\hline Question & $n(\%)$ \\
\hline \multicolumn{2}{|c|}{ Who was the $A D$ drawn up with?* } \\
\hline Self or family & $14(26.9)$ \\
\hline Family physician & $10(19.2)$ \\
\hline Lawyer & $32(61.5)$ \\
\hline No response & $2(3.7)$ \\
\hline \multicolumn{2}{|c|}{ Was the $A D$ brought to this ED visit? } \\
\hline Yes & $3(5.6)$ \\
\hline No & $40(74.0)$ \\
\hline No response & $11(20.4)$ \\
\hline \multicolumn{2}{|c|}{ Do you always bring the $A D$ to hospital visits? } \\
\hline Yes & $3(5.6)$ \\
\hline No & $51(94.4)$ \\
\hline \multicolumn{2}{|c|}{ Is family aware of the $A D$ ? } \\
\hline Yes & $47(87.0)$ \\
\hline No & $7(13.0)$ \\
\hline \multicolumn{2}{|c|}{ Is the family physician aware of the AD? } \\
\hline Yes & $28(51.9)$ \\
\hline No & $26(48.1)$ \\
\hline
\end{tabular}




\begin{tabular}{|c|c|c|c|c|}
\hline Item & $\begin{array}{l}\text { All participants } \\
(N=280) n(\%)\end{array}$ & $\begin{array}{l}\text { Canadian raised } \\
(n=164) n(\%)\end{array}$ & $\begin{array}{l}\text { ICU experienced } \\
(n=94) n(\%)\end{array}$ & $\begin{array}{l}\text { Perceived life-threatening } \\
\text { disease }(n=43) n(\%)\end{array}$ \\
\hline AD knowledge & $98(35.0)$ & 65 (39.6) & $33(35.1)$ & $19(44.2)$ \\
\hline AD ownership & 54 (19.3) & $38(23.2)$ & 18 (19.1) & 8 (18.6) \\
\hline Brought AD along & $3 / 54(5.6)$ & 2/38 (5.3) & 2/18 (11.1) & $0 / 8(0)$ \\
\hline $\begin{array}{l}\text { Think MD should know } \\
\text { wishes }\end{array}$ & 190 (67.9) & 109 (66.5) & $64(68.0)$ & $34(79.1)$ \\
\hline
\end{tabular}

would be interested in a service to discuss $\mathrm{ADs}$ in the future, 142 (50.7\%; 95\% CI 44.7-56.7) expressed an interest, $99(35.4 ; 95 \%$ CI 29.8-41.3) were not interested, and 39 (13.9\%) did not answer the question. Of those who indicated that they were interested in discussing ADs in the future, the majority stated that they would be most comfortable discussing this matter with family, friends, or a family doctor.

A logistic regression model indicated that the presence of an $\mathrm{AD}$ was independent of age, ability to perform independent activities of daily living, personal or secondary experience with the ICU, level of education, perception of the presence of a lifethreatening disease, or having a specialist physician.

\section{DISCUSSION}

We found that our study population had limited knowledge and ownership of ADs. Only 35.0\% of participants had knowledge of $\mathrm{ADs}, 19.3 \%$ had an $\mathrm{AD}$, and only $5.6 \%$ of this group brought their $\mathrm{AD}$ to the ED. None of the predefined covariates we examined were found to be associated with ownership of an $\mathrm{AD}$.

Our findings underscore a potential disconnection between advance health care planning and primary care. Of the participants who had ADs, only 19.2\% indicated that they had them drawn up with the help of their family doctor. Furthermore, of all participants

Table 4. Reasons why participants did not have an advance directive $(n=226)$

\begin{tabular}{lc|}
\hline Reason & $n(\%)$ \\
\hline Never thought about it & $107(47.3)$ \\
Prefer to let family decide & $36(15.9)$ \\
Not ready to make a decision & $27(11.9)$ \\
Need more information & $22(9.7)$ \\
Other (not specified) & $34(15.0)$ \\
\hline
\end{tabular}

who had ADs, only $56 \%$ reported that their family physician was even aware of their directives.

Our Canadian ED population had a higher rate of AD ownership than that found in an Australian study by Taylor and colleagues in 2003. ${ }^{7}$ This group conducted a cross-sectional study of 403 patients with a mean age of 73 years. They found that whereas $83 \%$ of their patients thought ADs were a good idea and $69 \%$ of patients would consider owning one, only $7.9 \%$ had one.

A 1997 study by Llovera and colleagues found that $27 \%$ of suburban New York ED patients (aged 1895 years) had ADs. ${ }^{8}$ In a follow-up study by the same group in 1999 , it was found that $23 \%$ of adults had ADs. Factors found to be predictive of having an $\mathrm{AD}$ were older age, having a specialist, having a lifethreatening medical problem, and not being Catholic. ${ }^{6}$ In another ED study of 238 patients in Tennessee, Ishihara and colleagues found that $22 \%$ of patients had ADs. ${ }^{5}$ Of these, $23 \%$ brought their ADs along for the ED visit.

There is sparse literature about the Canadian population's opinion of ADs. ${ }^{9,10}$ In 1993, Sam and Singer conducted a cross-sectional study of outpatients at two Canadian general internal medicine clinics. ${ }^{11}$ They determined that although $19 \%$ of patients in the study reported discussing some form of ADs, no patients reported having any written documentation. As for why patients did not have ADs, the authors suggested that reasons included illiteracy and the belief that $\mathrm{ADs}$ are unnecessary. When patients were asked about an appropriate time to initiate a discussion, $66 \%$ thought it should be dealt with during a routine visit with a family doctor, $50 \%$ at the onset of serious illness, and $39 \%$ at the time of admission to a nursing home.

To our knowledge, this is the first Canadian ED study of its kind, and we benefited from having a diverse patient population from a large metropolitan 
area. We chose to focus on patients over 70 years of age because we felt this group would be most likely to have thought about end-of-life issues and would derive the most potential benefit from having a documented $\mathrm{AD}$. Other studies have included adults of all ages, including young adults, with whom discussions of advanced care planning may not be as relevant or of interest. We made efforts to produce a survey instrument that was easy to comprehend, thus allowing it to be readily applied to our study population.

Several limitations must be considered when interpreting our results. Although our ED treats patients from a very wide variety of cultural, religious, and socioeconomic backgrounds, our study design inadvertently led to the selection of a very high-functioning group of elders. Most participants were well educated, and most were capable of performing not only their activities of daily living but also their own instrumental activities of daily living. Although we intended to enrol consecutive patients during our study hours, only a small minority of participants were institutionalized. Patients from nursing homes may have been less likely to be able to provide informed consent-be it for severe dementia, psychosis, altered mental status or delerium, acuity of illness, or lack of a surrogate decision maker or family member present in the ED. Furthermore, some patients were not enrolled because of high GTN workload during busy times in the ED. It is possible that during these busy times, GTN resources may have been diverted to patients who were more likely to be discharged home to the community as opposed to being admitted to hospital or discharged to a health care facility, where there would be further opportunities for patients to be evaluated by health care professionals.

We did not attempt to translate the survey instrument or enrol patients outside the working hours of the GTNs due to funding constraints.

Our study involved a difficult and emotionally charged subject, which undoubtedly deterred some patients from participating. Nearly one-third of eligible patients declined our invitation to participate in the study. Furthermore, some patients who enrolled in the study elected not to answer some questions, suggesting either a lack of understanding or possibly a lack of comfort with the subject matter.

An oversight in the design of the survey instrument left us unable to analyze for gender as we originally intended to do. We do not wish the negative findings of our logistic regression, or their contrast to the findings of other studies, to be overinterpreted. Given our sample size, this secondary analysis had limited power and may have failed to identify important associations.

The most appropriate advanced care planning occurs in the context of an ongoing relationship with a primary health care provider. Discussing $\mathrm{ADs}$ when a patient is hospitalized can be difficult because patients are typically admitted under the care of an unfamiliar physician. At times, discussions of ADs during an acute illness may be inappropriately interpreted as a prognosis.

When patients have made an effort to prepare ADs, there can be difficulties in accessing these ADs in times of crisis. ADs may not always be included in medical records, yet some patients may make the assumption that an emergency physician is aware of the content of previously established ADs simply because "it should be on the chart." Even if an AD is recorded, charts are not always available in a timely fashion when decisions need to be made. In the absence of a robust tracking system for ADs, well-intended discussions and documentation of $\mathrm{ADs}$ may ultimately be buried in the medical records. The availability of electronic medical records or a secure online database may help mitigate this problem and allow health care workers to respect patients' wishes when patients have taken the time and effort to document them beforehand, provided that robust and rapid retrieval mechanisms are incorporated into their design. ${ }^{12}$

Advanced care planning may be challenged by a lack of preparedness to discuss the topic by patients, families, and physicians. Patients may not be aware of the importance and value $\mathrm{ADs}$ offer in a setting such as the ED. In advocating for patient autonomy, policy makers who wish to promote advanced care planning and appropriate use of ADs should develop and fund both patient and physician education programs.

Future research in the area of advanced care planning should focus on patient and physician opinions on, experience with, and barriers to ADs. This research may include carrying out needs assessments at the community or health authority level. A need may exist for a structured approach, with an initial dialogue with patients and families either at a time of advancing age, the time of diagnosis of a terminal medical condition, admission to a hospital or long-term care facility, or a routine visit with a family 
physician. If family physicians are increasingly expected to initiate such discussions, fee structures and billing codes may require revision to encourage this. Moreover, a role may exist for specialized medical clinics designed for advanced health care planning involving physicians who have a particular interest or expertise in patient advocacy.

\section{CONCLUSION}

Knowledge of $\mathrm{ADs}$ among elderly patients visiting an urban Canadian ED is limited and is likely a significant factor precluding wider prevalence of ADs. There is interest in further discussion about $\mathrm{ADs}$ in this population group. Future research should focus on both patient and physician opinions on, experiences with, and barriers to ADs.

Acknowledgement: We wish to thank the dedicated team of geriatric triage nurses-Lil Chrzan, Liz Crane, Mary Fernandez, Joanne Hollis, and Jane Tillson-for their efforts in patient enrolment and data collection.

Competing interests: None declared.

\section{REFERENCES}

1. Wissow LS, Belote A, Kramer W, et al. Promoting advance directives among elderly primary care patients. 7 Gen Intern Med 2004;19:944-51, doi:10.1111/j.15251497.2004.30117.x.
2. Emauel L, Barry MJ, Stoeckle JD, et al. Advance directives for medical care- a case for greater use. N Engl 7 Med 1991; 324:889-95, doi:10.1056/NEJM199103283241305.

3. Cugliari AM, Miller T, Sobal J. Factors promoting completion of advance directives in the hospital. Arch Intern Med 1995;155:1893-8, doi:10.1001/archinte.1995. 00430170089011.

4. Stetler KL, Elliott BA, Bruno CA. Living will completion in older adults. Arch Intern Med 1992;152:954-9, doi:10.1001/ archinte.1992.00400170044008.

5. Ishihara KK, Wrenn $\mathrm{K}$, Wright $\mathrm{SW}$, et al. Advance directives in the emergency department: too few, too late. Acad Emerg Med 1996;3:50-3, doi:10.1111/j.1553-2712. 1996.tb03303.x.

6. Llovera I, Ward MF, Ryan JG, et al. Why don't emergency department patients have advance directives? Acad Emerg Med 1999;6:1054-60, doi:10.1111/j.1553-2712. 1999.tb01192.x.

7. Taylor D McD, Ugoni AM, Cameron PA, et al. Advance directives and emergency department patients: ownership rates and perceptions of use. Int Med $\mathcal{F}$ 2003;22:586-92.

8. Llovera I, Mandel F, Ryan J, et al. Are emergency department patients thinking about advance directives? Acad Emerg Med 1997;4:976-80, doi:10.1111/j.1553-2712. 1997.tb03663.x.

9. Molloy DW, Guyatt G, Alemayhu E, et al. Treatment preferences, attitudes towards advance directives and concerns about health care. Hum Med 1991;7:285-90.

10. Molloy DW, Guyatt GH. A comprehensive health care directive in a home for the aged. CMA7 1991;145:307-11.

11. Sam M, Singer PA. Canadian outpatients and advance directives: poor knowledge and little experience but positive attitudes. CMA7 1993;148:1497-502.

12. Freer JP, Eubanks M, Parker B, et al. Advance directives: ambulatory patients knowledge and perspectives. $\mathrm{Am} 7 \mathrm{Med}$ 2006;119:1088.e9-13, doi:10.1016/j.amjmed.2006.02.028. 